\title{
Emergência e desenvolvimento de espécies nativas em área degradada por disposição de resíduos sólidos urbanos
}

Luana Auxiliadora de Resende ${ }^{1}$

Lilian Vilela Andrade Pinto ${ }^{2}$

\section{Resumo}

O crescimento acelerado da população juntamente com o atual padrão de vida vivenciados nas últimas décadas vêm trazendo diversos impactos ambientais e sociais. Na maioria dos municípios a disposição de resíduos sólidos urbanos (RSU) é descartada em áreas sem prévio tratamento ou fiscalização adequada, que quando são desativadas encontram-se degradadas e necessitam da elaboração de um plano de recuperação e revegetação, além do monitoramento, ao longo dos anos, para avaliar o desenvolvimento das espécies implantadas. Todavia estes problemas podem ser minimizados, principalmente se houver a recuperação do local atingido. Sendo assim, o presente estudo visou avaliar a emergência das espécies arbóreas semeadas na cova e em sulco aos 90 dias, e o desenvolvimento das plântulas emergidas aos 210 e 300 dias, podendo assim avaliar as espécies que melhor se adaptam à condição da área do lixão de Inconfidentes-MG. 0 experimento foi instalado no delineamento estatístico inteiramente casualizado com 3 tratamentos de semeadura direta, com 15 espécies arbóreas nativas e três repetições (T1: semeadura direta de espécies nativas em cova; T2: semeadura direta de espécies nativas em sulco através de muvuca; T3: semeadura direta de espécies nativas associadas com feijão-guandu em sulco através de muvuca). 0 modelo de plantio que tem a associação de sementes de espécies arbóreas com feijão-guandu em sulco (T3) é o método mais indicado para a recuperação de áreas de lixões. As espécies arbóreas que se destacaram quanto à emergência e estabelecimento foram Schizolobium parahyba (guapuruvu) e Eritrina speciosa (molungu).

Palavras-chave: Semeadura direta. Muvuca. Feijão-guandu.

\section{Introdução}

A recuperação das áreas degradadas é uma atividade que vem sendo implantada em diversas regiões do Brasil. A degradação causada pela redução da cobertura vegetal é, geralmente, resultado de ações antrópicas e ocasiona perda da biodiversidade e das funções de um ecossistema, sendo assim, acarreta em um total desequilíbrio para fauna e flora, além de afetar o desenvolvimento socioeconômico da região.

O crescimento populacional nas últimas décadas, principalmente após a revolução industrial, trouxe diversas consequências que são prejudiciais ao meio ambiente, acarretando um aumento de áreas degradadas devido ao mau uso do solo e de seus recursos naturais. Uma das atividades que causa uma grande preocupação para a sociedade é a disposição incorreta de resíduos sólidos

\footnotetext{
1 Tecnóloga em Gestão Ambiental - Graduanda em Engenharia Agronômica pelo IFSULDEMINAS, campus Inconfidentes, Praça Tiradentes, 416, centro, Inconfidentes/MG. CEP 37576-000 - luanaaresende@gmail.com

2 Professora doutora do IFSULDEMINAS, campus Inconfidentes, Praça Tiradentes, 416, centro, Inconfidentes/MG. CEP 37576-000lilianvap@gmail.com
} 
urbanos (RSU). Estima-se que no Brasil existam 1.688 lixões que recebem em torno de 22 milhões de toneladas de lixo por ano (FANTÁSTICO, 2011). Estes locais estão sendo contaminados com o chorume, um líquido altamente poluente, originado da decomposição de resíduos orgânicos. Quando em contato com a chuva, o seu volume aumenta e é escoado para o solo, lençol freático e leito de rio, gerando fortes impactos ambientais (ALBERTE et al.; 2005).

Ao encerrar as atividades de deposição de resíduos sólidos, os locais ficam sem vegetação e inertes a qualquer atividade, sendo estes fatos relatados por vários municípios como uma situação problemática (BELI et al.; 2005). Conforme Souza (2007) é importante que seja feita a recuperação das áreas afetadas pelo RSU através de vegetação, para mitigar os impactos causados pela disposição destes resíduos de forma inadequada, o que deveria ser feito em aterros sanitários. A vegetação, além de evitar as erosões, pode promover o retorno da fauna e a reconstituição paisagística do local.

Assim, fica evidente que promover uma gestão adequada das áreas de disposição de resíduos é umas das melhores formas de tratamentos e a busca de soluções tem envolvido, sobretudo, a recuperação técnica, social e ambiental de áreas de depósitos de RSU inadequadas (ALBERTE et al., 2005).

Uma técnica que vem dando certo e está sendo utilizada em elevada ascensão na recuperação de áreas degradadas, de acordo com Alvarenga (2004) citado por Oliveira (2009), é a semeadura direta, em que as sementes são semeadas diretamente no solo. Esse método vem se destacando devido ao seu baixo custo e ao alto poder germinativo. Sendo assim a utilização de novas técnicas é importante devido às grandes áreas que devem ser recuperadas, fato que abrange e enriquece as propriedades afetadas (CAMPOS; AMADOR; AZEVEDO, 2011).

No município de Inconfidentes, localizado no Sul de Minas Gerais, que conta com uma população estimada de 6.904 habitantes (IBGE, 2010), o lixo coletado (3,5 ton./dia) vem sendo disposto a montante da área experimental (antigo lixão) em uma área de 3,77ha (PREFEITURA DE INCONFIDENTES, 2011), sendo importante um estudo que ajude na recuperação da antiga área de deposição de RSU no local. Assim, o presente estudo visou avaliar o desenvolvimento de espécies arbóreas semeadas por diferentes tratamentos aos 90 dias, e o desenvolvimento das plântulas emergidas aos 210 e 300 dias, podendo assim avaliar as espécies que melhor se adaptam à condição da área do lixão de Inconfidentes-MG.

\section{Material e métodos}

O experimento de recuperação da área do lixão foi desenvolvido no município de Inconfidentes, MG, que segundo a classificação de KOËPPEN possui clima do tipo tropical úmido (Cwb), com duas estações definidas: chuvosa (outubro a março) e seca (abril a setembro). Há predomínio de verões brandos e chuvosos, com temperatura média de $22^{\circ} \mathrm{C}$ e índices pluviométricos entre 1400 e 1700 $\mathrm{mm} / \mathrm{ano}^{-1}$. Os invernos são frios e secos, marcados por temperaturas médias de $16,5^{\circ} \mathrm{C}$ e índices pluviométricos entre 140 e $170 \mathrm{~mm}$.

Em outubro de 2010, foram implantados 3 tratamentos de semeadura direta com 15 espécies arbóreas nativas (Tabela 1 ), sendo o $1^{\circ}$ tratamento com semeadura de sementes nativas arbóreas em cova ( $\mathrm{T} 1$ ), o $2^{\circ}$ tratamento com semeadura de sementes das espécies nativas arbóreas misturadas em sulco (T2) e o $3^{\circ}$ tratamento com semeadura das sementes das espécies nativas arbóreas associadas com a leguminosa feijão-guandu em sulco (T3). No T1 foram semeadas 10 sementes por cova, com espaçamento de $1 \times 1$, totalizando 15 covas por parcela de $3 \mathrm{~m}$ de largura por $5 \mathrm{~m}$ de comprimento. Já nos tratamentos em sulco, o comprimento das linhas de semeadura é de 1,66 m, onde foram semeadas 10 sementes de cada espécie nativa arbórea, misturadamente no T2 (muvuca 1) e 10 sementes de cada espécie nativa arbórea em sulco associadamente com 15 gramas (200 
sementes) de feijão-guandu no T3 (muvuca 2). Cada tratamento foi avaliado com base em resultados de 3 repetições. Existiu um controle quanto à emergência, onde foi utilizado um tratamento como testemunha, implantando no viveiro da fazenda IFSULDEMINAS, campus Inconfidentes, as mesmas espécies de sementes que havia no campo.

Tabela 1. Espécies implantadas nos tratamentos de semeadura direta na área do lixão.

\begin{tabular}{ccccc}
\hline Nome Científico & Nome Comum & Nome Científico & Nome Comum \\
\hline Lithraea molleoides (Vell.) Engler & aroeira-brava & Solanum lycocarpum A.St.-Hil. & lobeira \\
\hline Schinus terebinthifolius Raddi & aroeira-vermelha & Brosimum glazioui Taubert & marmelinho \\
\hline Machaerium nictitans (Vell.) Benth & bico-de-pato & Erithrina speciosa Andrews & molungu \\
\hline Cordia ecalyculata Vell. & café-de-bugre & Acacia polyphylla DC. & monjoleiro \\
\hline Solanum granuloso-leprosum Dunal & capoeira-branca & Bauhinia forficata Link & pata-de-vaca \\
\hline Senna multijuga (Rich.) Irwin et Barn. & cássia-carnaval & Aspidosperma subincanum Mart. & pereira-de-campo \\
\hline Schizolobium parahyba (Vell.) Blake. & Guapuruvu & Paratecoma peroba Record Kuhlm & peroba \\
\hline Jacaranda cuspidifolia Mart. & jacarandá-branco & Cajanus cajan (L.) Millsp & feijão-guandu \\
\hline
\end{tabular}

Fonte: Elaboração própria.

Foram avaliados os parâmetros de emergência e de desenvolvimento das plântulas nos diferentes tratamentos (cova e sulco). A quantificação da emergência das plântulas nas covas e no sulco foi avaliada 90 dias após a semeadura direta. Foram consideradas plântulas emergidas aquelas que apresentaram os protófilos visíveis. 0 desenvolvimento das espécies foi avaliado a partir da mensuração da altura e do diâmetro do coleto das plântulas aos 210 dias ( 7 meses) e aos 300 dias (10 meses) após serem semeadas em campo.

Para avaliar as possíveis alterações da fertilidade do solo e como estas poderiam interferir na emergência e no desenvolvimento silvicultural das plântulas foram realizadas 3 análises químicas do solo (Tabela 2) durante os 10 meses de avaliação da área.

Tabela 2. Análises químicas do solo da área do Lixão de Inconfidentes, durante a condução do experimento de recuperação da área.

\begin{tabular}{|c|c|c|c|c|c|c|c|c|c|c|}
\hline Análises & $\mathrm{pH}$ & ${ }^{*} \mathbf{P}$ & *K & ${ }^{*} \mathrm{Ca}$ & ${ }^{*} \mathrm{Mg}$ & ${ }^{*} \mathrm{H}+\mathrm{Al}$ & *SB & ${ }^{*}$ CTC & $\mathrm{V} \%$ & ${ }^{* *} \mathrm{M} .0$ \\
\hline $1^{\text {a }}$ (nov-2010) & 6,19 & 8,0 & 76 & 1,4 & 0,70 & 1,61 & 2,3 & 3,9 & 58,8 & 1,08 \\
\hline $2^{\mathrm{a}}(\mathrm{fev}-2011)$ & 5,82 & 4,8 & 123 & 1,8 & 0,95 & 1,74 & 2,5 & 4,8 & 63,9 & 0,61 \\
\hline $3^{a}$ (mai-2011) & 6,42 & 2,1 & 137 & 1,7 & 0,70 & 1,37 & 2,8 & 4,1 & 66,7 & 1,19 \\
\hline Média & 6,14 & 4,97 & 112 & 1,63 & 0,78 & 1,57 & 2,53 & 4,27 & 63,1 & 0,96 \\
\hline
\end{tabular}

${ }^{*} \mathrm{Cmol} / \mathrm{dm}^{3 * *} \mathrm{~g} / \mathrm{dm}^{3}$

Fonte: IFSULDEMINAS - campus Inconfidentes, laboratório de análise de solos.

A primeira avaliação foi realizada em novembro de 2010, no início do experimento, e revelou que o solo apresentava baixos níveis de fósforo $(P)$, matéria orgânica (M.O) e valores médios para potássio (K). Esta análise foi tomada como base para a comparação entre os nutrientes disponíveis às plantas ao longo do experimento. A segunda análise ocorreu no mês de fevereiro de 2011 , após alguns dias sem chuvas para amostrar solo seco. Vale ressaltar que durante o período chuvoso (novembro de 2010 a fevereiro de 2011), que totalizou 1083.3mm de precipitação (Figura 1), o solo esteve diretamente em contato com o chorume proveniente do lixo, o que interferiu no $\mathrm{pH}$, que estava mais ácido do que nas demais avaliações. Já a terceira e última coleta de solo ocorreu no mês de 
maio. Nesta análise houve um aumento do $\mathrm{pH}$, que continua ácido, do potássio $(\mathrm{K})$ e da matéria orgânica (M.O) em relação às demais análises.

Os dados diários da ocorrência de precipitação de outubro de 2010 a agosto de 2011 foram disponibilizados pela companhia de abastecimento do município de Inconfidentes/MG (COPASA), tornando possível identificar a precipitação total mensal durante o período do experimento (Figura 1).

Figura 1. Precipitação pluviométrica registrada durante outubro de 2010 a agosto 2011 - Inconfidentes/MG.

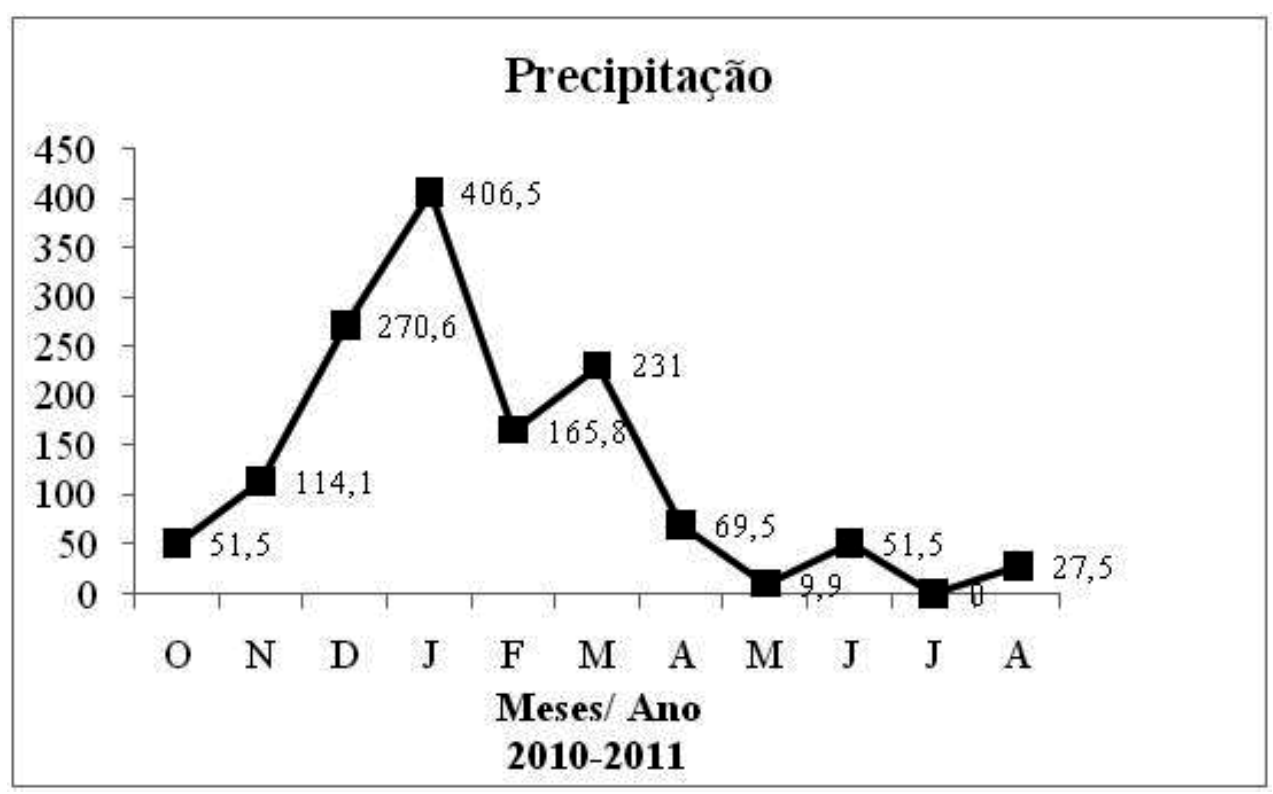

Fonte de dados: COPASA

\section{Resultados e discussão: avaliação da emergência, sobrevivência e dos parâmetros silviculturais da semeadura direta}

\section{Percentual de emergência após 90 dias da semeadura direta nos diferentes tratamentos}

A semeadura das espécies na área do lixão desativado ocorreu em outubro e após 90 dias foi avaliada a emergência (Figura 2). Dentre as 15 espécies que germinaram em sementeira no viveiro, apenas 11 emergiram no campo, podendo-se inferir que as condições de solo e clima do lixão interferem na taxa de emergência das espécies (RESENDE; PINTO, 2011). As espécies Schizolobium parahyba (guapuruvu), Eritrina speciosa (molungu), Solanum lycocarpum (lobeira) e Schinus terebinthifolius (aroeira-vermelha) germinaram nos 3 tratamentos (T1- Semeadura direta de espécies nativas em cova; T2- Semeadura direta de espécies nativas em sulco através de muvuca e T3- Semeadura direta de espécies nativas em sulco associadas com feijão guandu através de muvuca). As espécies Senna multijuga (cássia-carnaval), Platyajanum reginelii (pereira), Lithraea molleoides (aroeira-brava) e Aspidosperma parviflora (peroba) germinaram em condições controladas de umidade no viveiro, mas não germinaram na área do lixão (RESENDE; PINTO, 2011). Segundo Nassif, Vieira e Fernandes (1998), para que haja germinação é fundamental uma sequência de eventos fi- 
siológicos que são influenciados por fatores externos e internos, sendo que cada um pode atuar por si ou em interação com os demais, sendo a umidade, a luz, a temperatura e a dormência os principais fatores que afetam o estágio inicial da germinação, podendo assim destacar que algumas das espécies implantadas na área de estudo não se adequaram ao ambiente proposto.

Figura 2. Emergência das espécies arbóreas após 90 dias de implantação em diferentes tratamentos de semeadura direta.

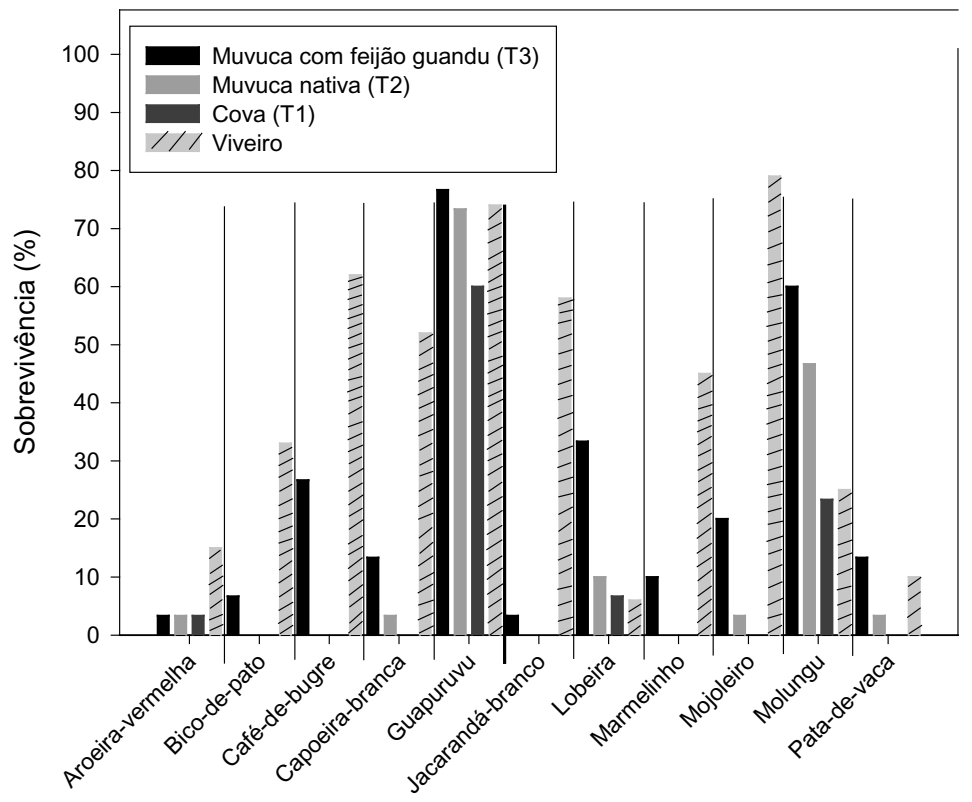

Fonte: Elaboração própria

Fazendo uma comparação com a taxa de germinação das espécies semeadas no viveiro com as espécies semeadas na área em recuperação do lixão, verificou-se que apenas as espécies Schizolobium parahyba (guapuruvu), Jacaranda cuspidifolia (jacarandá-branco), Solanum granuloso-leprosum (capoeira-branca), Acácia poliphyle (monjoleiro) e Cordia ecalyculata (café-de-bugre) apresentaram pelo menos $50 \%$ da germinação observada em condições controladas quanto à disponibilidade de água e de sombrite utilizada para a interceptação da luz solar (RESENDE; PINTO, 2011). Já as espécies Eritrina speciosa (molungu) e Solanum lycocarpum (lobeira) se destacaram quanto à emergência ocorrida no campo, havendo uma diferenciação entre esta e a germinação do viveiro, fato que pode ser justificado segundo as observações de Rodrigues e Gandolfi (2004) e Vasconcelos, Paula e Vasconcelos (2009), respectivamente, que afirmam que estas espécies têm uma alta taxa de emergências de plântulas e um caráter mais rústico.

Dentre os tratamentos de semeadura direta, o que apresentou maior número de espécies emergidas foi o T3 (Semeadura direta de espécies nativas em sulco associadas com feijão guandu através de muvuca). Neste tratamento, das 15 espécies implantadas, 10 (67\%) emergiram aos 90 dias, sendo elas guapuruvu $(63,33 \%)$, molungu $(30 \%)$, capoeira-branca $(26,67 \%)$, café-de-bugre $(26,67 \%)$, lobeira $(16,67 \%)$, pata-de-vaca $(13,33 \%)$, aroeira-brava $(6,67 \%)$ e aroeira-vermelha (3,33\%). Esta boa taxa de emergência corrobora a afirmação de Campos, Amador e Azevedo (2011), de que a muvuca com a junção do feijão-guandu, uma leguminosa de porte arbustivo, tem a função de fazer o sombreamento e de proteger as espécies arbóreas nativas em fase inicial de emergência, tendo a mesma função das pioneiras. Já no tratamento T2 (semeadura direta de espécies nativas em sulco através de muvuca), apenas 5 espécies (33,33\%) emergiram: guapuruvu (60\%), molungu 
$(63,33 \%)$, lobeira $(6,67 \%)$, pata-de-vaca $(3,33 \%)$ e aroeira-vermelha $(3,33 \%)$.

A semeadura direta em cova proporcionou baixa taxa de emergência, podendo ter sido influenciada pela época de implantação, que ocorreu no período chuvoso, tendo precipitado 791,2 mm de novembro de 2010 a janeiro de 2011 (Figura 1), quantidade de água por metro quadrado que deixou parte das covas encharcadas, e não por erro técnico quanto à quantidade de sementes semeadas por cova (10), visto que esta equivale à quantidade recomendada por Ferreira et al. (2009), e pelo fato de as sementes terem passado por tratamentos pré-germinativos, quando necessário, antes da semeadura.

\section{Percentual de sobrevivência após 210 e 300 dias da semeadura direta nos diferentes tratamentos na área degradada}

A avaliação da sobrevivência das espécies nativas emergidas aos 300 dias após a semeadura direta (Figura 3B) apresentou pouca diferença entre o percentual de sobrevivência das plântulas emergidas aos 210 dias (Figura 3A).

A semeadura direta em cova (T1) não mostrou ser uma boa opção para a recuperação de solos de lixão, tendo possibilitado a sobrevivência de apenas uma espécie (guapuruvu - 50\%) (6,67\% das espécies semeadas) aos 300 dias após a semeadura das sementes.

No T2 (semeadura direta de espécies nativas em sulco através da muvuca) as espécies emergidas (40\% das semeadas) tiveram a mesma taxa de sobrevivência durante os 3 meses de comparação, sendo de 3,3\% para aroeira-vermelha, capoeira-branca e pata-de-vaca, 10\% para a lobeira, $55,33 \%$ para o molungu e $70 \%$ para o guapuruvu. Os valores de mesmo percentual de emergência possibilitam inferir que as espécies estabelecidas plantadas por semeadura direta adaptaram-se às condições edafoclimáticas do local.

Figura 3. Sobrevivência das espécies arbóreas em diferentes tratamentos de semeadura direta. A) Avaliação aos 210 dias após terem sido semeadas; B) Avaliação aos 300 dias após terem sido semeadas.
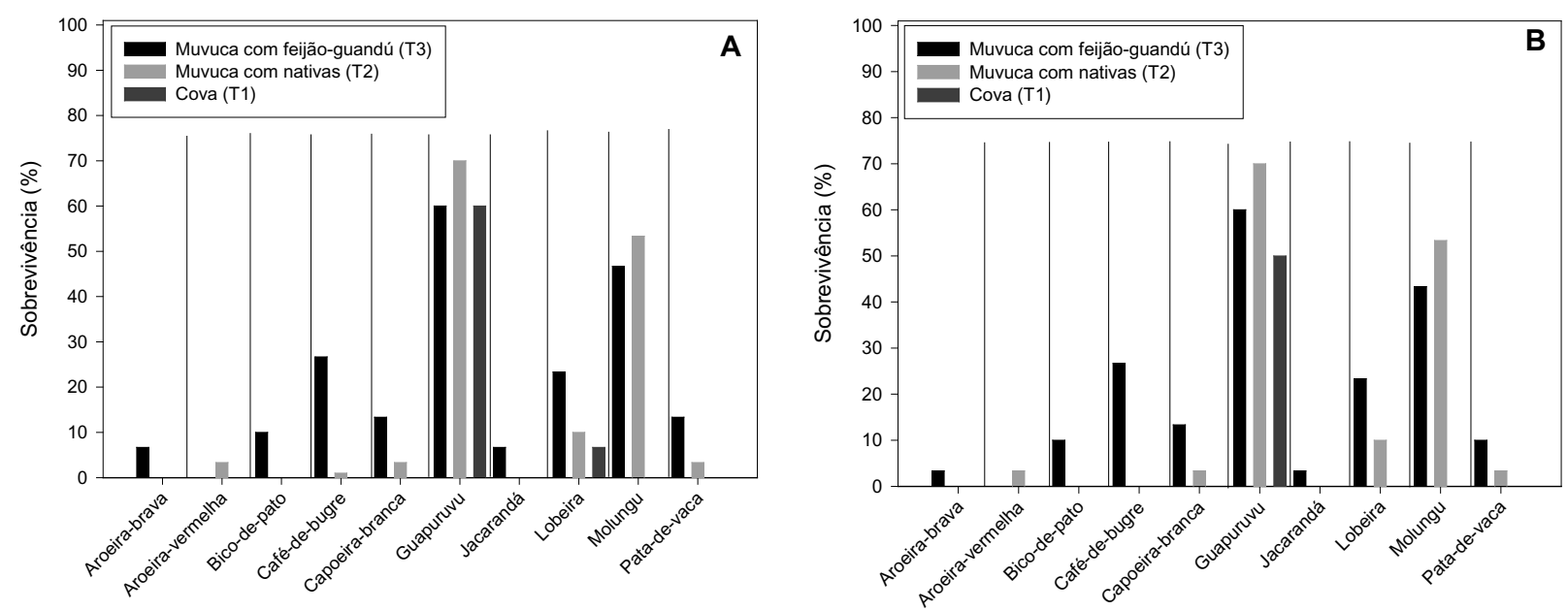

Fonte: Elaboração própria

Vale destacar que apenas duas espécies tiveram uma taxa de pegamento acima de 50\% (guapuruvu e molungu) das 15 espécies avaliadas no T2 (semeadura direta de espécies nativas em sulco através de muvuca). Segundo Matheus e Lopes (2007), as sementes do guapuruvu apresentam 
dormência, sendo necessários tratamentos pré-germinativos. A alta taxa germinativa deve-se, então, à imersão em água a $99^{\circ} \mathrm{C}$ a que a espécie foi sujeita antes de ir para o campo. Para Vasconcelos, Paula e Vasconcelos (2009), o molungu tem uma alta taxa de emergências de plântulas e um caráter mais rústico, comprovando então o seu grande poder germinativo e de sobrevivência. Este bom desenvolvimento que as espécies estabeleceram se deve ao poder germinativo e de adaptabilidade, corroborando a literatura que indica estas espécies para locais degradados.

A baixa porcentagem de sobrevivência das espécies aroeira-vermelha, capoeira-branca, lobeira e pata-de-vaca aos 210 e 300 dias no T2 (semeadura direta de espécies nativas em sulco através de muvuca) (Figura $3 \mathrm{~A}$ e B) estão relacionadas à baixa porcentagem de emergência que foi registrada aos 90 dias (Figura 2).

Já no T3 (semeadura direta de espécies nativas associadas com feijão-guandu em sulco através de muvuca), apesar de apenas o guapuruvu ter tido uma sobrevivência acima de $50 \%$ aos 300 dias da semeadura, apresentando $60 \%$ de emergência, as espécies que também se estabeleceram foram aroeira-brava e jacarandá-branco (3,33\%), bico-de-pato e pata-de-vaca (10\%), capoeira-branca $(13,33 \%)$, lobeira $(23,33 \%)$, café de bugre $(26,67 \%)$ e molungu $(43,33 \%)$ (Figura 3B). Neste tratamento, 9 espécies (60\%) estabeleceram-se no local, tornando esta técnica mais enriquecida quando comparada a técnica em cova (T1) (6,67\%) e a semeadura sem consórcio com leguminosas, com apenas nativas (T2) (40\%). Este enriquecimento de maiores números de espécies deve-se ao consórcio da leguminosa feijão-guand, que tem um ciclo curto, dando condições e funções de espécies pioneiras da primeira fase, ou seja, recobre o solo e sombreia as plântulas que vão emergir, tornado o método mais seguro onde é mais provável a germinação e sobrevivência das nativas no decorrer da recuperação (CAMPOS; AMADOR; AZEVEDO, 2011).

O uso da técnica de recuperação de áreas degradadas por muvuca de espécies nativas com leguminosas vem crescendo nos dias atuais e ganhando espaço principalmente nos locais onde a área para a recuperação é grande (GLOBO RURAL, 2010).

\section{Avaliação da altura (H) e do diâmetro altura do solo (DAS) das espécies se- meadas diretamente na área degradada}

A avaliação do desenvolvimento (altura e diâmetro altura do solo) das espécies semeadas no campo ocorreu após 120 e 210 dias da contagem da emergência das plântulas. Observou-se pequena diferença no crescimento das espécies em comum (capoeira-branca, guapuruvu, lobeira, molungu e pata-de-vaca) nos tratamentos T2 (semeadura direta de espécies nativas em sulco através de muvuca) e T3 (semeadura direta de espécies nativas associadas com feijão-guandu em sulco através de muvuca). As espécies guapuruvu e lobeira foram as que desenvolveram melhor em altura e diâmetro do solo (Figura 4). Este crescimento diferencial corrobora o estudo de Lorenzi (2002), em que relata que o guapuruvu é uma espécie de desenvolvimento rápido, principalmente na fase inicial. Já em relação à lobeira, Vidal, Stacciariniseraphin e Câmara (1999) destaca que a espécie desenvolve em condições ambientais desfavoráveis, tais como terras ácidas e pobres em nutrientes, condições encontradas na área, como pode ser observado nas análises químicas do solo (Tabela 2). 
Figura 4. Avaliação dos parâmetros silviculturais para a semeadura direta A) Desenvolvimento da altura $(\mathrm{H})$; B) Desenvolvimento do diâmetro altura do solo (DAS).
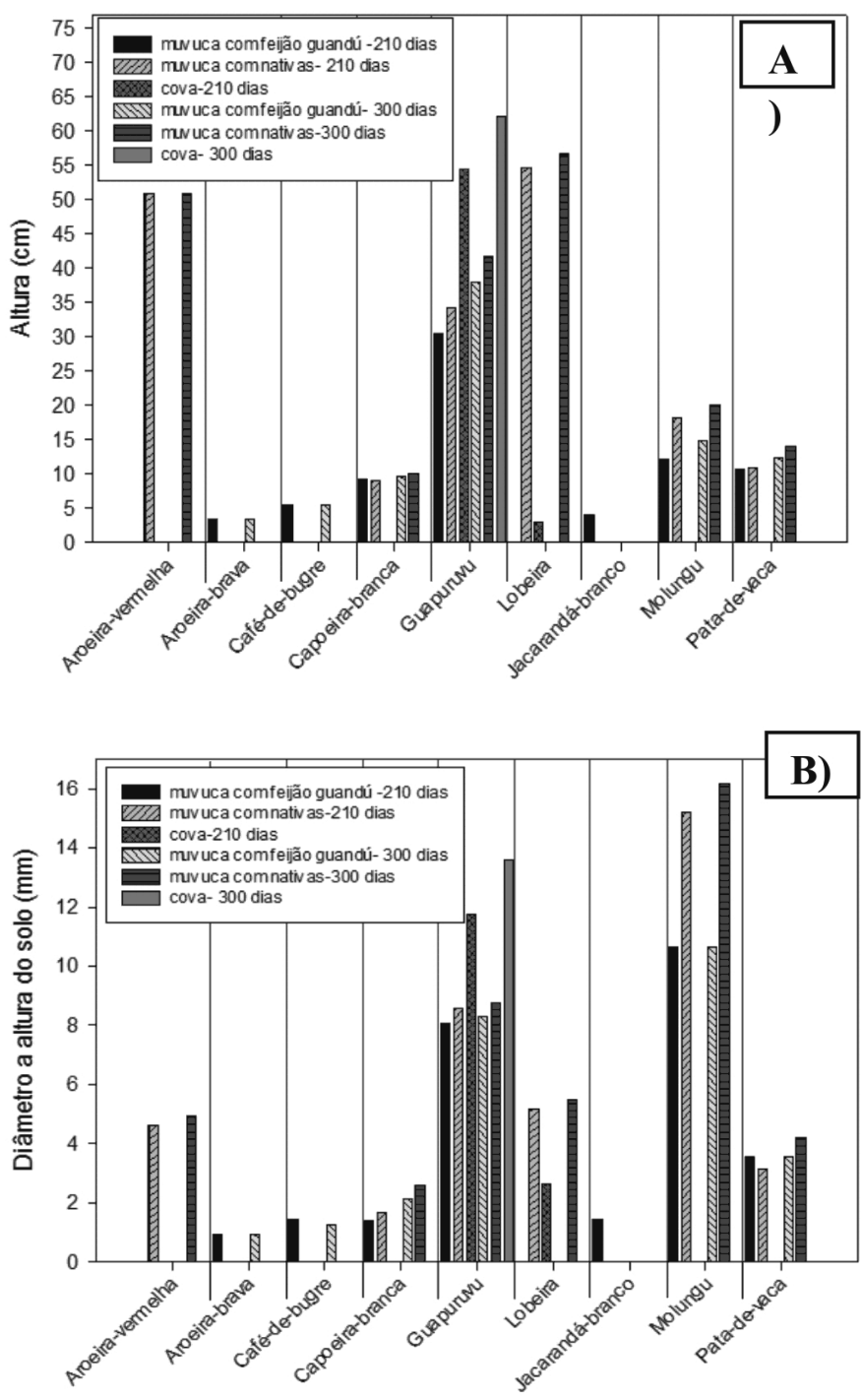

Fonte: Elaboração própria

As espécies capoeira-branca e pata-de-vaca apresentaram um crescimento inicial baixo em comparação com as duas espécies relatadas acima, tanto em altura como em diâmetro altura do solo. Essa diferença pode ser explicada pela baixa fertilidade do solo da área experimental, não permitindo uma adequada nutrição mineral inicial das espécies (DAVIDE; FARIA; BOTELHO, 1995) e por ter um desenvolvimento mais lento quando comparadas ao guapuruvu e à lobeira. Ainda, esse menor crescimento pode estar associado a fatores externos, que segundo Santana (2007) a toxidade que o chorume tem, faz com que o desenvolvimento da microbiota seja menor juntamente com 0 desenvolvimento da geminação das sementes e do crescimento das plantas nesses locais, que ficam diretamente em contato com o líquido.

A espécie aroeira-vermelha apresentou uma altura média de $51 \mathrm{~cm}$ aos 7 meses, podendo ser considerado um crescimento significativo quando comparado à altura de $91 \mathrm{~cm}$ observada por Souza (2007) após 12 meses da semeadura em uma área degradada, sendo considerada pelo pesquisador uma espécie de crescimento rápido. 
Os tratamentos T2 (semeadura direta de espécies nativas em sulco através de muvuca) e T3 (semeadura direta de espécies nativas associadas com feijão-guandu em sulco através de muvuca) não interferiram no desenvolvimento em altura e em diâmetro a altura do solo das espécies, quando comparado um com o outro. Esta afirmação se deve, segundo Cruz et al. (2002), a fatores edafoclimáticos iguais em que as espécies são submetidas durante o período avaliado.

Com estes resultados, verificou-se que o feijão-guandu em consórcio com as espécies nativas tem interferência na emergência, mas não no crescimento das plântulas emergidas.

\section{Conclusões}

A partir da análise dos resultados da recuperação da área do lixão de Inconfidentes, MG, conclui-se que a técnica da muvuca proporcionou melhores resultados, podendo então ser utilizada para revegetar áreas de lixões com as características edafoclimáticas que não diferenciem das do local estudado.

A associação de sementes de espécies arbóreas com leguminosas herbáceas em sulco (T3) é a melhor opção para a recuperação de áreas de lixões por meio da semeadura direta, visto o feijão-guandu ter influenciado positivamente na emergência (66\% das espécies), mas não no crescimento das plântulas emergidas.

A semeadura direta de espécies nativas em cova (T1) proporcionou baixa taxa germinativa, não sendo indicada para esses locais.

Nos tratamentos com semeadura direta, as espécies Schizolobium parahyba (guapuruvu), Eritrina speciosa (molungu), Solanum lycocarpum (lobeira) e Schinus terebinthifolius (aroeira-vermelha) destacaram-se quanto à emergência aos 90 dias da semeadura, no entanto ao avaliar a sobrevivência aos 300 dias da semeadura, apenas Schizolobium parahyba (guapuruvu) e Eritrina speciosa (molungu) encontravam-se estabelecidas.

\section{Emergence and development of native species in degraded areas for urban waste disposal}

\section{Abstract}

The rapid population growth with the current way of life from the late decades has raised diverse environmental and social impacts. The urban solid waste disposal (USW) in the greatest part of the cities is achieved in areas without previous treatment or adequate oversight, and when inactivated they are degraded and in need of a recovery and reforestation plan, and also monitoring for some years to evaluate the development of the species implanted. However, these problems can be minimized, mainly if the recovery of the area is achieved. Thus, the present study aimed to evaluate the emergence of arboreal species sown in burrow and groove in three stages: 90 days and the plant development after 210 and 300 days, making it possible to evaluate the species that best adapted to the conditions of the landfill area in Inconfidentes- MG. The experiment was made in the completely randomized experimental design with 3 direct sowing treatments with 15 arboreal native species and three repetitions (T1: direct sowing of native species in burrow; T2: direct sowing of native species in groove using muvuca ; T3: direct sowing of native species associated with pigeon pea in groove 
using muvuca). The planting model of associated native species with pigeon bea in groove (T3) is the most indicated model for the landfill recovery. The arboreal species that stand out for emergence and stablishment were Schizolobiumparahyba (guapuruvu) and Eritrinaspeciosa (molungu).

Keywords: Direct sowing. Muvuca. Pigeon pea.

\section{Agradecimentos}

Ao CNPq pelos recursos financeiros para a execução do projeto "Revegetação de áreas de lixões por diferentes técnicas de regeneração artificial" e ao IFSULDEMINAS, Campus Inconfidentes, pela concessão da bolsa e equipamentos complementares.

\section{Referências bibliográficas}

ALBERTE, E. P. V.; CARNEIRO, A.P.; KAN, L. Recuperação de áreas degradadas por disposição de resíduos sólidos urbanos. Diálogos e Ciência. Feira de Santana, Ano III, n. 5, jun. 2005. Disponível em <http://www.bvsde.paho.org/bvsacd/cd48/areas.pdf> Acesso em: 02 fev. 2011.

BELI, E. et al. Recuperação da área degradada pelo lixão Areia Branca de Espírito Santo o Pinhal . Engenharia Ambiental, Espírito Santo do Pinhal , v.2. n1, p/140 e 141, jan./dez. 2005.

CAMPOS, R. J. B.; AMADOR, D. B.; AZEVEDO, V. A. A experiência da fazenda São Luiz com plantios agroflorestais mecanizados: relato de experiência, 2010. Disponível em <http://www. fazendasaoluiz.com>. Acesso em: 27 de julho 2011.

CRUZ, J. E. et al. Projeto ribeirão da cachoeira em Espírito Santo do Pinhal-SP. Revista Ecossistema, Espírito Santo do Pinhal, v.27, n.1/2, jan./dez. 2002.

DAVIDE, A.C.; FARIA, J.M.R.; BOTELHO, S.A. Propagação de espécies florestais. Belo Horizonte: CEMIG/UFLA/FAEPE, 1995.

FANTÁSTICO, 2011. Em todo o Brasil, 72\% das cidades jogam o lixo em lugares inadequados. Disponível em: <http://fantastico.globo.com/Jornalismo/FANT/0,MUL1646151-15605,00.html>. Acesso em: 6 fev. 2011.

FERREIRA, R. A. et. al. Semeadura direta com espécies florestais na implantação de mata ciliar no Baixo São Francisco em Sergipe. Scientia Forestalis, Piracicaba, v. 37, n. 81, p. 37-46, mar. 2009. Disponível em <http://www.ipef.br/publicacoes/scientia/nr81/cap04.pdf> Acesso em: 15 fev. 2011.

Globo Rural, 2010. Reflorestamento no Xingu: técnica da muvuca acelera reflorestamento nas nascentes do rio Xingu. Disponível em <http://globoruraltv.globo.com/GRural/0,27062,L T00-4370-341807-1,00.html> Acesso em: 09 de out. 2010.

IBGE. Instituto Brasileiro de Geografia e Estatística (IBGE) 2010. Disponível em < http://www. ibge.gov.br/home/> Acesso em: 26 out. 2010. 
LORENZI, H. Árvores brasileiras: manual de identificação e cultivo de plantas arbóreas nativas do Brasil. 4 ed. Nova Odessa: Instituto Plantarum de Estudos da Flora, 2002.

MATHEUS, M. T. e LOPES, J. C. Termoterapia em sementes de guapuruvu (Schyzolobium parahyba (Vell.) Blake). Revista Brasileira de Biociências, v. 5, s.2, p. 330-332, 2007. Disponível em <http://www.ufrgs.br/seerbio/ojs/index.php/rbb/article/view/303/265>. Acesso em: 01 de fev., 2011.

NASSIF, S.M.L.; VIEIRA; I.G, FERNANDES, G.D. Fatores Externos (Ambientais) que influenciam na germinação de sementes. Informativo de Sementes IPEF, Piracicaba, abril 1998. Disponível em <http://www.ipef.br/tecsementes/germinacao.asp>. Acessado em: 03 de fev., 2011.

OLIVEIRA, F., Avaliação de diferentes métodos de regeneração na recuperação de nascentes. 2009. Monografia (Graduação). Instituto Federal de Educação, Ciência e Tecnologia do Sul de Minas Gerais, campus Inconfidentes, Inconfidentes.

SECRETARIA MUNICIPAL DE AGRICULTURA E MEIO AMBIENTE. Prefeitura Municipal de Inconfidentes. Inconfidentes: 2011.

RESENDE, L. A. e PINTO, L. V. A.. Semeadura direta na recuperação do lixão de Inconfidentes/MG. In: JORNADA CIENTÍFICA E TECNOLÓGICA, 03, 2011. Machado. Anais... III Jornada Científica e Tecnológica, 2011 (CD-ROM).

RODRIGUES, R.R.; GANDOLFI, S. Conceitos, tendências e ações para a recuperação de florestas ciliares. In: RODRIGUES, R.R.; LEITÃO FILHO, H.F. (Orgs.). Matas ciliares: conservação e recuperação. São Paulo: EDUSP/FAPESP, 2004, p.235-247.

SANTANA, O. A. Influência de depósito de lixo na Fitossociologia das espécies arbóreas de cerrado. 2007. 113p. Dissertação (Doutorado). Universidade de Brasília, Brasília.

SOUZA, C. M. Recuperação de áreas degradadas em aterros sanitários. 2007. Monografia (Graduação). Universidade Federal Rural do Rio de Janeiro, Seropédica.

VASCONCELOS, P. B.; PAULA, C. L.; VASCONCELOS, H. L. Resposta morfológica de solanum lycocarpum aos efeitos da Herbivoria e estresse hídrico. 2009. Monografia (Graduação). Universidade Federal de Uberlândia. Uberlândia.

VIDAL, M.C.; STACCIARINISERAPHIN, E.; CÂMARA, H.H.L.L. Crescimento de plântulas de Solanum lycocarpum St. Hil. (lobeira) em casa de vegetação. Acta Botanica Brasílica, v. 13, p. 271-275, 1999.

\section{Histórico editorial}

Recebido: 17/09/2012

Avaliação e copidesque: 21/09/2012 a 05/04/2013 